\title{
Opioid: toward an effective strategy for better use
}

Yeon-Dong $\mathrm{Kim}^{1,2}$ ${ }^{1}$ Department of Anesthesiology and Pain Medicine, Wonkwang University School of Medicine, Iksan,
2Jesaeng-Euise Clinical Anatomy Center, Wonkwang University School of Medicine, Iksan, Korea

Opioids are the oldest medicine, coming down to us from ancient times, and the best pain reliever. As the detailed mechanisms of action became clear in modern times, studies on opioids have become more active, and many new opiate drugs have been introduced in clinical trials. Until the 1990s, opioids were used only in the treatment of moderate to severe acute or cancer pain, but their recent long-term use to relieve non-cancer pain has been increasing [1]. As opioids theoretically have no ceiling effect, and are partly effective for almost all kinds of pain, they must be an attractive option to treat chronic pain that doesn't respond to other painkillers.

Ten years after the WHO issued its final guidelines for the control of cancer pain with opioids in 1986, it was reported that $69 \%-100 \%$ of cancer pain was properly controlled [2]. The WHO's guidelines later provided a platform allowing opioids in the treatment of cancer pain, thus enhancing the quality of life for patients. Opioids have also started being used for chronic non-cancer pain, with clinical reports that opioids are effective and less likely to become addictive in patients with no history of mental disease, or alcohol or drug abuse [3]. Several published guidelines and consensus statements recommend judicious use of opioids in appropriately selected patients with chronic non-cancer pain who have not responded to other treatments and analgesic medications [4].

Nonetheless, there remains uncertainty about the optimal use of opioids. Some patients do not experience significant improvements in pain or function even on high doses of opioids and long-term use may lead to side effects. Besides serious issues such as addiction and abuse, the most common side effects are predictable consequences of opioid pharmacological actions, and include nausea, vomiting, constipation, pruritus, dizziness, dry mouth, and sedation in daily use. Guidelines for the responsible use of opioids in chronic non-cancer pain also reflect concern over these problems [5].

The utility value of opioids has not yet been fully realized due to public bias or a lack of clinical experience in drug therapy. Differences were also noted by region, specialty, and the requirement for the use of multiple prescriptions of opioids. It is estimated that this is based on differences in individual physicians' clinical experience in regards to various side effects [6].

Chronic pain, unlike acute pain, should itself be recognized as a disease entity. It is a bio-psychosocial state that requires a comprehensive and multidisciplinary approach to its assessment and treatment [7]. Therefore, the

Received March 12, 2019. Accepted March 12, 2019.

Correspondence to: Yeon-Dong Kim

Department of Anesthesiology and Pain Medicine, Wonkwang University School of Medicine, Wonkwang University Hospital, 895 Muwang-ro, Iksan 54538, Korea

Tel: +82-63-859-1562, Fax: +82-63-857-5472, E-mail: kydpain@hanmail.net

ORCID: https://orcid.org/0000-0003-0404-2657

(c) This is an open-access article distributed under the terms of the Creative Commons Attribution Non-Commercial License (http:// creativecommons.org/licenses/by-nc/4.0/), which permits unrestricted non-commercial use, distribution, and reproduction in any medium, provided the original work is properly cited.

(c) The Korean Pain Society, 2019 
most basic and important principle is that improved quality of life, such as pain reduction and functional recovery, which can be achieved by taking opioids, should outweigh the side effects. Proper selection and use of opioids is very important, even in order to improve the patient's quality of life and to advance the completion of treatment. Between $50 \%$ and $80 \%$ of patients in clinical trials experience at least one side effect from opioid therapy, however in everyday use the incidence may be even higher [8].

Opioid induced constipation (OIC) is one of the most common side effects, which is another obstacle to overcome. Although not fatal, frequent constipation is pointed out as an important cause of drug discontinuation. It will have a serious impact on the effectiveness of opioid use, and can be an important reason for physicians' reluctance to use opioids in clinical practice.

In this issue of the Korean Journal of Pain (KJP), Bornemann-Cimenti [9] reviews OIC, and proposes a new strategy for better use of opioids in the management of pain. A review of OIC through the diagnosis, traditional treatment, and introduction of newer treatment options is provided. The suggested algorithm for clinical management of OIC will be a useful reference for clinical application based on the guidelines provided in the KJP [10]. Successful management of side effects will initiate a new look at the value of opioid use.

\section{CONFLICT OF INTEREST}

No potential conflict of interest relevant to this article was reported.

\section{REFERENCES}

1. Noble M, Treadwell JR, Tregear SJ, Coates VH, Wiffen PJ, Akafomo C, et al. Long-term opioid management for chronic noncancer pain. Cochrane Database Syst Rev 2010; (1): CD006605.

2. Jadad AR, Browman GP. The WHO analgesic ladder for cancer pain management. Stepping up the quality of its evaluation. JAMA 1995; 274: 1870-3.

3. Moulin DE, lezzi A, Amireh R, Sharpe WK, Boyd D, Merskey $H$. Randomised trial of oral morphine for chronic non-cancer pain. Lancet 1996; 347: 143-7.

4. The use of opioids for the treatment of chronic pain. A consensus statement from the American Academy of Pain Medicine and the American Pain Society. Clin J Pain 1997; 13: 6-8.

5. Kalso E, Allan L, Dellemijn PL, Faura CC, llias WK, Jensen TS, et al. Recommendations for using opioids in chronic non-cancer pain. Eur J Pain 2003; 7: 381-6.

6. Hamunen $\mathrm{K}$, Laitinen-Parkkonen P, Paakkari P, Breivik $H$, Gordh $\mathrm{T}$, Jensen $\mathrm{NH}$, et al. What do different databases tell about the use of opioids in seven European countries in 2002? Eur J Pain 2008; 12: 705-15.

7. Siddall PJ, Cousins MJ. Persistent pain as a disease entity: implications for clinical management. Anesth Analg 2004; 99: 510-20.

8. Moore RA, McQuay HJ. Prevalence of opioid adverse events in chronic non-malignant pain: systematic review of randomised trials of oral opioids. Arthritis Res Ther 2005; 7 : R1046-51.

9. Lang-llievich K, Bornemann-Cimenti $H$. Opioid-induced constipation: a narrative review of therapeutic options in clinical management. Korean J Pain 2019; 32: 69-78.

10. Kim ED, Lee JY, Son JS, Byeon GJ, Yeo JS, Kim DW, et al. Guidelines for prescribing opioids for chronic non-cancer pain in Korea. Korean J Pain 2017; 30: 18-33. 